Mehdi Yadegari', Simin Riahy², Shadmehr Mirdar', Gholamreza Hamidian ${ }^{3}$, Seyed Mohsen Afkhami ${ }^{4}$, Ayoub Saeidi ${ }^{5}$, Fatma Rhibi ${ }^{6}$, Abderraouf Ben Abderrahman ${ }^{7}$, Anthony C. Hackney ${ }^{8}$, Hassane Zouhal ${ }^{6}$

'Department of Exercise Physiology, Faculty of Physical Education and Sport Sciences, University of Mazandaran, Mazandaran, Iran

${ }^{2}$ Faculty of Aerospace Medicine and Subsurface, Army Medical University, Tehran, Iran

${ }^{3}$ Department of Basic Sciences, Faculty of Veterinary Medicine, University of Tabriz, Tabriz, Iran

${ }^{4}$ Colonel Physician, Army Ground Forces, Health Relief and Treatment Center, Teheran, Iran

${ }^{5}$ Department of Biological Sciences in Sport, Faculty of Sports Sciences and Health, Shahid Beheshti University, Teheran, Iran

${ }^{6}$ Université de Rennes, M2S, Laboratoire Mouvement, Sport, Santé, Rennes, France

${ }^{7}$ Higher Institutes of Sport and Physical Education of Ksar-Said, Ksar-Said, Tunisia

${ }^{8}$ Department of Exercise \& Sport Science, University of North Carolina, Chapel Hill, NC, USA

\title{
The TNF- $\alpha$, P53 protein response and lung respiratory changes related to exercise, chronic hypoxia and Adiantum capillus-veneris supplementation
}

\begin{abstract}
Introduction: Evidence suggests that hypoxia and high-intensity exercise training can increase apoptosis of lung cells and Adiantum capillus-veneris (Ac-v) extract can have anti-apoptotic effects. Thus, the aim of the present study was to investigate the effect of chronic hypoxia and the (Ac-v) extraction as a supplement on TNF- $\alpha$ and P53 protein expression as well as the respiratory surface.

Material and methods: 24 healthy Wistar rats (age $=4$ weeks, weight $=72=9 \mathrm{gr}$ ) were trained using interval training for 6 weeks followed by a 3-week stay in hypoxia conditions. Half of the hypoxia samples received $500 \mathrm{ml} / \mathrm{gr} / \mathrm{per}$ body weight daily (Ac-v) within 3 weeks of hypoxia. At the end, the lung tissue was removed for histological and immunohistological analysis.

Results: After 3 weeks of hypoxia exposure following 6 weeks of exercise, expression of P53 and TNF- $\alpha$ increased and the respiratory surface decreased $(p \leq 0.05)$. After 3 weeks of taking the Ac-v extract during hypoxia exposure, reduced P53 and TNF- $\alpha$ expression and the increased respiratory surface were observed $(p \leq 0.05)$.

Conclusions: Chronic hypoxia may be considered as a strong stimulus leading to the expression of proteins involved in apoptosis and tissue disruption. However, our findings suggest that the antioxidative properties of Ac-v extract could decrease the destructive structural and molecular events that happen along with hypoxia exposure or intense exercise training.
\end{abstract}

Key words: apoptosis, lung, interval training, respiratory surface

Adv Respir Med. 2019; 87: 226-234

\section{Introduction}

Hypoxia is defined as a lack of oxygen delivery resulting in an inability to maintain physiological function [1]. Different organs such as the lungs, heart, vessels and skeletal muscles respond dramatically to any kind of reduced oxygen delivery [2]. Studies in both animals and humans in hypoxia conditions have shown changes in alveolar features because of hypoxia exposure. Some researchers have reported that lung cells could be involved in apoptosis in hypoxia conditions [3]. On the other hand, there is some evidence that there is an increase in cell growth as a result of hypoxia [4]. In the acute and chronic lung disorders, the apoptosis induced by hypoxia has serious clinical consequences [5]. In fact, apoptosis as programed cell death is a physiological process in which cells might die unconsciously regardless of their growth status or other biological processes [6]. This kind of death would happen more probably in tissue hemostasis

Address for correspondence: Hassane Zouhal, Univ Rennes, M2S (Laboratoire Mouvement, Sport, Santé), EA 1274, F-35000 Rennes, France;

e-mail: hassane.zouhal@univ-rennes2.fr

DOI: 10.5603/ARM.2019.0037

Received: 23.12.2018

Copyright (C) 2019 PTChP

ISSN 2451-4934 
and embryogenesis [7]. Evidence suggests that due to hypoxia exposure, glucocorticoids and free radicals increase intracellular calcium, TNF- $\alpha$ and P53, leading to an increase in apoptosis signals within lung cells [8, 9].

On the other hand, strenuous exercise modulates several related factors, such as reactive oxygen species (ROS), DNA damage, and hormone and cytokine levels, which are involved in the regulation of apoptosis in various cell types. Furthermore, ROS that increase in correspondence with the enhanced oxygen uptake during exercise are able to induce apoptosis via different mechanisms such as a decrease in intracellular glutathione levels or an alteration of mitochondrial proteins or by direct damage to cellular DNA [27].

Normally, harm to DNA results in defects in P53 function. P53 activation as a prevention of transcriptional factor of the cellular cycle can stop cellular proliferation. In fact, the accumulation of P53 leads to binding to DNA, which causes two major effects: 1) cellular cycle stopped in G1 phase so the cell caught up the opportunities to repair any kind of damages; 2) If damaged DNA could not repair itself successfully, apoptosis genes such as BAX (BCL2 associated X) were activated so this could lead to mitochondria- dependent apoptosis $[10,11]$. In addition to this, the TNF receptors family is considered to be the most important cell death receptors. If linked to procaspase 8 and then caspase 8 (active form), it could become the active caspase signaling cascade [12].

In long-term exercise training conditions or hypoxia conditions, if the anti-apoptotic and antioxidant system cannot deal with the situation [13, 14], using nutrition and supplements such as antioxidants and anti-inflammatory supplements could be a good strategy to protect cells from oxidative stress [15]. Adiantum capillus-veneris (Ac-v) is a widely distributed plant species extensively used in traditional Chinese folk medicine for a variety of diseases. Ac-v Linn is a graceful delicate fern found in damp places of the western Himalayas, as one ascends to an altitude of 2,400 $\mathrm{m}$, and extending into Manipur. It is common in Punjab, Bihar, Maharashtra, and South India. Capillus veneris Linn is traditionally used in the Unani system of medicine for the treatment of inflammatory diseases [42]. (Ac-v) is a plant supplement (extract) having flavonoids, terpenoids, saponins and polyphenols which play an antioxidative role and are applied in inflammatory disorders such as asthma [16]. Since the mechanisms of inflammation are correlated with apoptosis, it is possible that using (Ac-v) could decrease apoptotic effects of hypoxia , and hence bring benefits to lung tissue.

Athletes are reported to use hypoxia to improve their physiological adaptation to exercise training. Hence, inflammatory complications of severe exercise and hypoxia in the lungs have also been reported. Consequently, the present study aims to answer the question if being in hypoxia conditions and high-intensity exercise training would affect the TNF- $\alpha$ and P53 protein expression and also, to investigate histological adaptations in the respiratory surface and to study the role of (Ac-v) extract supplementation in these adaptations.

\section{Materials and methods}

The study was carried out in accordance with the National Institutes of Health Guide for the care and use of laboratory animals. All experiments that involved animals were conducted according to the policy of the Iranian convention for the protection of vertebrate animals used for experimental and other scientific purpose, and the protocol was approved by the ethics committee of the Sciences, University of Mazandaran (UMZ) (number: 2316813 and date: 18/2/2016).

\section{Animals}

Twenty-four Wistar male healthy rats (age = 4 weeks, height $=72 \pm 8$ gr) were obtained from the Amol Pasteur Institute and were moved to our laboratory. The rats were completely healthy in terms of physical well-being, with no history of disease.

The animals were randomly divided into 3 groups, including; control $(\mathrm{n}=8)$, hypoxia $(\mathrm{n}=8)$ and hypoxia and supplement $(\mathrm{n}=8)$. After the animals were moved to the laboratory, the first week was considered a familiarization with the laboratory standard conditions, and in the second week, they were acquainted with the treadmill. They were provided with a standard amount of food and water.

\section{Exercise training protocol}

The training program consisted of 10 intervals, including 1-2 minutes exercise and active rest each, in a way that, resting speed was half of the exercise $(25 \mathrm{~m} / \mathrm{m}$ in the first week and $70 \mathrm{~m} / \mathrm{m}$ in the last week). The animals performed an exercise plan in 5 sessions in a week. After finishing the first 6 weeks, the animals were moved to a hypoxia chamber (a chamber with the same condition as $\mathbf{2 8 0 0}$ meters altitude) for the next three 
weeks. Half of the hypoxia animals received the (Ac-v) extraction at a dose of $500 \mathrm{ml} / \mathrm{kg}$ per body weight daily $[17,44]$, which was administered by gavage. The (Ac-v) extraction was made according to the procedures of Wendakoon et al. [18].

\section{Tissue sampling}

Lung sampling was done 48 hours after the last hypoxia day. In order to do this, 3 units of ketamine $(30-50 \mathrm{mg} / \mathrm{kg}$ ) and xylacin $(3-5 \mathrm{mg} / \mathrm{kg}$ ) were injected into them. After, the lung tissue was removed and immersed in 10 percent formalin. After 5 days of the fixed tissue First, by using the orientiotor technique armed with IUR principles, the lungs were cut from the lung tissue and using passive stages [with the help of the automatic method of histocyte model (2000) made by the Leika Company] and paraffin molds prepared with the use of a rotating microtome model 820 with slices of 5 micrometers in thickness for immunohistochemical studies. The pilot study results were used to determine the first section and minimum intervals between the sections. The molecular analyses including oriento analysis were done according to Schneider et al. [19]. Five laminates were randomly divided into five non-sequential thin sections with a thickness of $5 \mu \mathrm{m}$ for immunohistochemical examination of TNF- $\alpha$ protein expression and five other thin slices for immunohistochemical examination of P53 protein expression.

\section{Immunohistochemical analysis}

The immunohistochemical technique was performed using the TNF- $\alpha$ specific antibody code ab9635 made by Abcam Company and P53 code M7001 made by Dako Company. To do this, briefly, after preparing the paraffin sections and placing them on the syllabized slides of the S3003 code of Dako and during the de-paraffin dehydration steps with desiccation of alcohol, the antigen retrieval was performed using the Tris/EDTA buffer and the microwave. After washing and pre--treatment with a $3 \%$ hydrogen peroxide solution in methanol and washing with phosphate buffer solution and determining the cut-off area with Daco pencil, the antibody was added to the tissue and after treatment with peroxidase- labeled polymer, the cut surface was chromatographed with $\mathrm{DAB}$ and its substrate was covered. After complete rinsing and differential chromatography with hematoxylin, the slides were protected by optical microscopy [20]. Then, using each microscope slider, five different fields were selected and taken. Using each microscope slide, five different fields were chosen and taken with the camera. Finally, the images were analyzed for the quality of the reaction by Image Moore software version 1.49. They were described as random data [21].

\section{Stereological analysis}

Stereological studies were applied to determine the changes in the respiratory surface in the lung tissue [22], using optic-fractional methods with a microscope attached to a micro-monitor, a camera, and a full-digital system, with a version 9 of the Stereo-investigator software. The estimated respiratory surface was determined using a linear probe with the following formula: Salv lung $=$ Sv (alv/par $) \times \operatorname{Vd}($ par/lung $) \times$ Vlung

Volumetric parenchymal pulmonary density and "Vlung" are the total volume of the left lung, which was previously calculated according to the Cavalier method, and "SV (alv/par)" is the surface density (relative to the internal surface) of the alveoli, calculated by the following formula:

Where "I" represents the number of collisions in target level with the lines, "p" represents the number of points in the reference space and " $\mathrm{l} / \mathrm{p}$ " is the length of each line in degree.

\section{Extraction of Adiantum capillus-veneris (Ac-v)}

A total of $500 \mathrm{~g}$ of (Ac-v) fresh plant was shade dried, powdered and extracted with ethanol for 6-8 hours using a Soxhlet extraction apparatus. The extraction process was done by packing $50 \mathrm{~g}$ of fine powder with Whatmann filter paper No. 41 and placing that in the Soxhlet extraction apparatus along with solvent - petroleum ether, and then methanol. This extract contains both polar and non-polar phytocomponents. Table 1 shows Ac-v weight in the extraction process $[18,23]$.

\section{GC-MS analysis of (Ac-v)}

A total of $5 \mathrm{ml}$ of the extract was evaporated to dryness and re-dispersed into $2 \mathrm{ml}$ methanol. The extracts were then subjected to GC-MS analysis. Chromatographic separation was carried out with a GC-MS-QP 2010 [SHIMADZU] instrument with Db 30.0 column $(0.25 \mu \mathrm{m}$ diameter $\times 0.25 \mu \mathrm{m}$ in thickness). The oven temperature was programed from $70^{\circ} \mathrm{C}$ (isothermal for $5 \mathrm{~min}$ ), with an increase of $10^{\circ} \mathrm{C} / \mathrm{min}$, to $200^{\circ} \mathrm{C}$, then $5^{\circ} \mathrm{C} / \mathrm{min}$ to $280^{\circ} \mathrm{C}$, ending with a $35 \mathrm{~min}$ isothermal at $280^{\circ} \mathrm{C}$. Mass spectra were taken at $70 \mathrm{eV}$; a scan interval of $0.5 \mathrm{~s}$ and scan range from $40-1000 \mathrm{~m} / \mathrm{z}$. Helium was used as carrier gas at $99.999 \%$ pressure with flow $1.0 \mathrm{ml} / \mathrm{min}$ and electronic pressure control on. The samples were dissolved in methanol and injected automatically. The main components of the Ac-v measured by GS-MS are shown in Table 2 [18, 23]. 


\section{Statistical analysis}

Descriptive statistics were used to measure the mean and standard deviations in the groups. The Kolmogorov-Smirnov test (k-s) was applied to assess data distribution normality. The groups' means were compared with one-way ANOVA followed by Least Significant Difference (LSD) tests - post hoc analysis. All calculations were performed using SPSS 21.0 software, and significance was set at $\mathrm{P} \leq 0.05$.

\section{Results}

Statistical analysis showed that after a 3-week exposure to hypoxia after an interval-training period (hypoxia group), the TNF- $\alpha$ expression

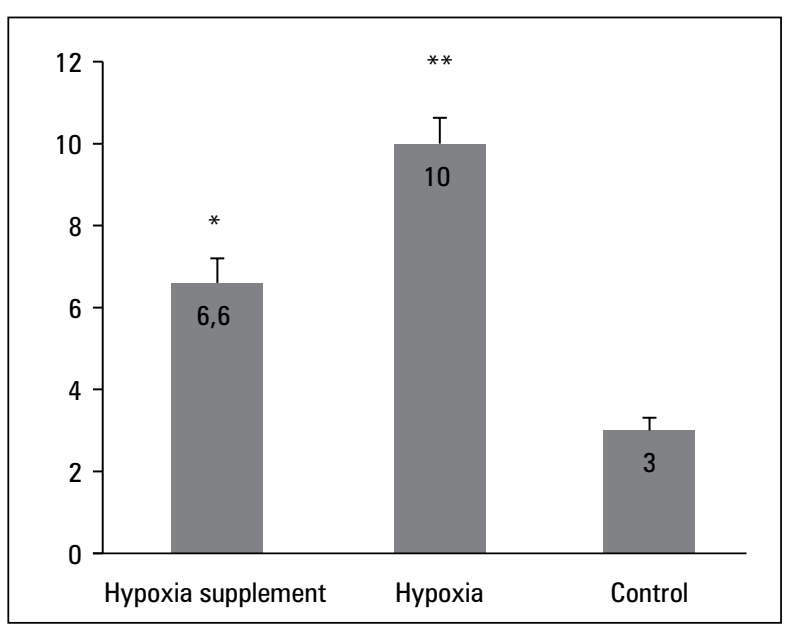

Figure 1. Levels of TNF- $\alpha$ parenchymal protein in the 3 studied groups Data are means \pm SE.

*Significant difference compared to the control group $(P \leq 0.05)$; **Significant difference compared to the exercise-hypoxia group $(\mathrm{P} \leq 0.05)$ of the lung parenchyma increased significantly compared to the control group (233.33\%, $\mathrm{P} \leq 0.05$ ) (Figure 1, 2). It was also observed that the level of this protein in the supplemental hypoxia group has significantly decreased compared to the hypoxia group $(\mathrm{P} \leq 0.05)$.

P53 parenchymal protein expression increased significantly $(344.82 \%, \mathrm{p} \leq 0.05)$ (Figure 3, 4). As seen in Figure 3, P53 expression in the hypoxia group was significantly increased compared to the control group $(\mathrm{P} \leq 0.05)$. However, the level of this protein in the supplemental hypoxia group was significantly decreased compared to the hypoxia group $(\mathrm{P} \leq 0.05)$.

The respiratory surface of the lung parenchyma decreased significantly $(56.46 \%, \mathrm{p} \leq 0.05)$ (Figure 5,6). As seen in Figure 5, the respiratory surface in the hypoxia group was significantly reduced compared to the control group $(\mathrm{P} \leq 0.05)$. It was also observed that the respiratory surface in the supplemental hypoxia group was significantly increased compared to the hypoxia group $(P \leq 0.05)$. As seen in Figure 6, the structure of the parenchymal segment of the lung tissue in the control group was normal, while in the hypoxia group, the number of pulmonary alveoli decreased. Also, the number of pulmonary alveoli in the hypoxia group was increased compared to the hypoxia group.

The analysis showed that the (Ac-v) extract in the supplemental hypoxia group for 3 weeks compared to the hypoxia group resulted in a significant decrease of the TNF- $\alpha$ expression of the lung parenchyma $(34 \%, \mathrm{p} \leq 0.05)$ (Figure 1,2$)$. The results also showed that the protein expression of the P53 parenchyma significantly decreased $(41.08 \%, p \leq 0.05)$ (Figure 3, 4). The respiratory surface of the lung parenchyma increased significantly $(36.57 \%, \mathrm{p} \leq 0.05)$ (Figure 5, 6).

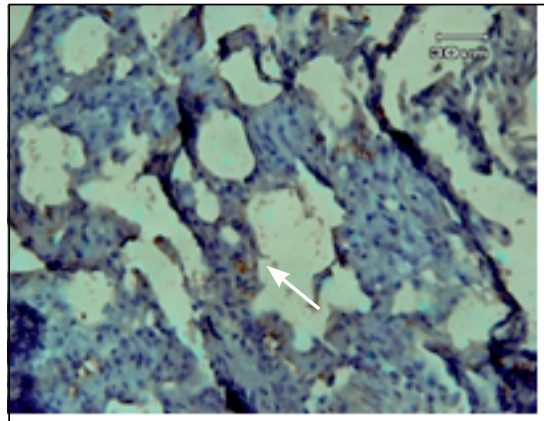

Hypoxia supplement

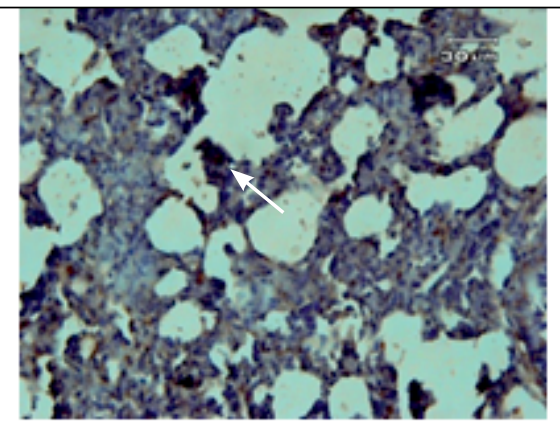

Hypoxia

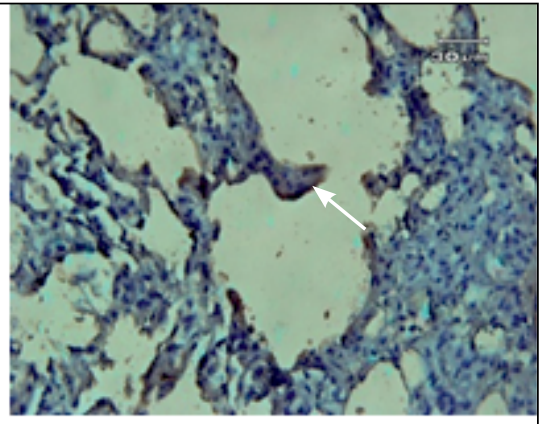

Control

Figure 2. Micrograph of lung tissue in the 3 studied groups. The secondary antibody TNF- $\alpha$ is attached to FITC and the cell core is painted with PI color. Zoom in on a $400 \times$ scale. The arrow in the images (yellow color reaction) indicates a positive reaction with antibody. The color intensity scale in pixel units per micrometer square (Pixel $/ \mu \mathrm{m}^{2}$ ). As it is seen, the expression of TNF- $\alpha$ protein in the hypoxia group has increased compared to the control group and decreased in the hypoxia supplement group as compared to the hypoxia group 


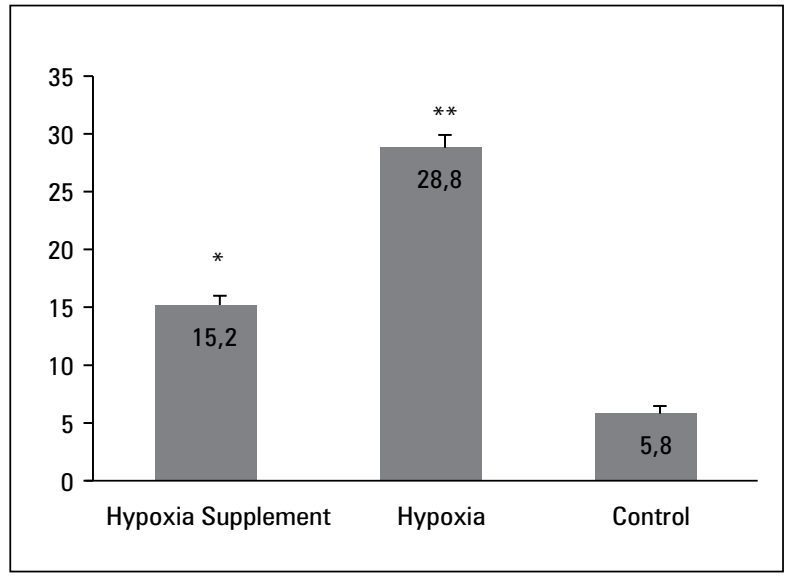

Figure 3. Levels of P53 protein in the 3 studied groups. Data are means \pm SE.

*Significant difference compared to the control group $(\mathrm{P} \leq 0.05) ;{ }^{*} \mathrm{Si}-$ gnificant difference compared to the exercise-hypoxia group $(P \leq 0.05)$

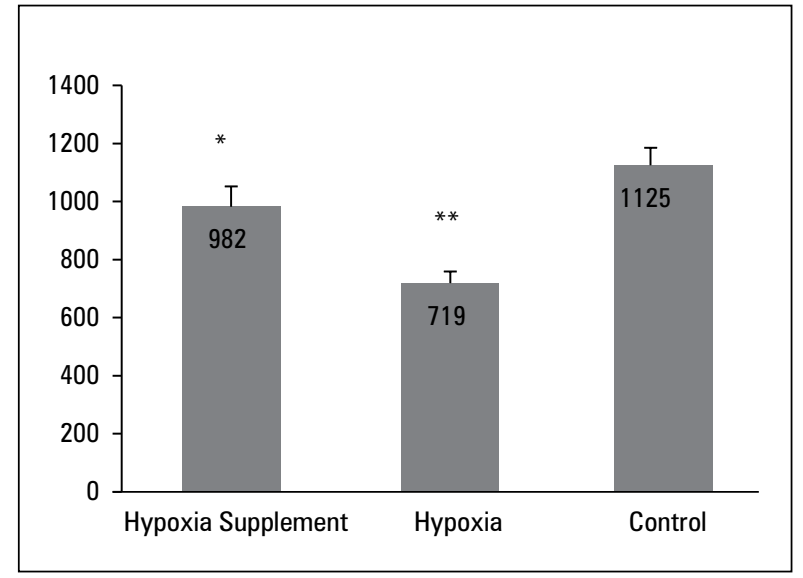

Figure 5. The respiratory surface of the lung in the 3 studied groups. Data are means $\pm \mathrm{SE}$.

*Significant difference compared to the control group $(\mathrm{P} \leq 0.05)$; * $\mathrm{Si}$ gnificant difference compared to the exercise-hypoxia group $(\mathrm{P} \leq 0.05)$

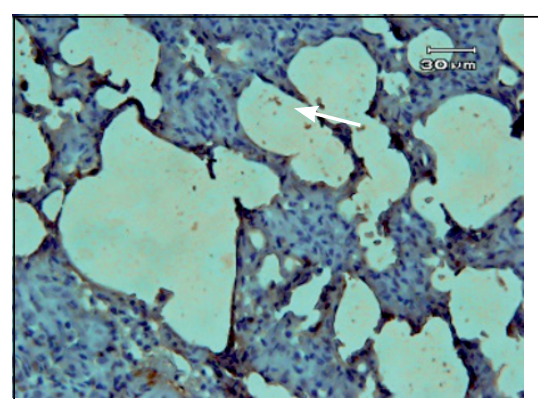

Hypoxia supplement

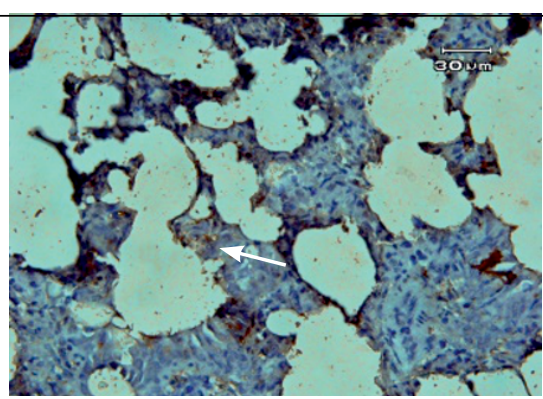

Hypoxia

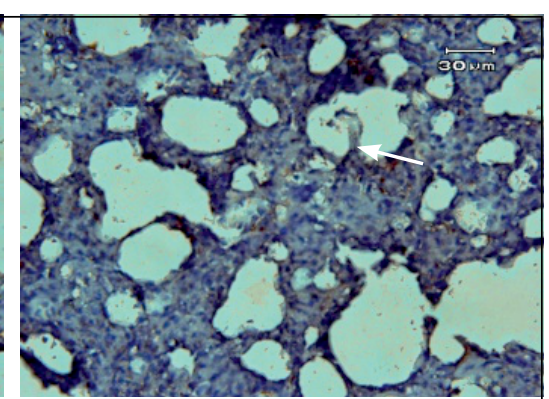

Control

Figure 4. Micrograph of lung tissue in the 3 studied groups. The secondary P53 antibody is attached to FITC and the cell core is painted with PI color. Zoom in on a $400 \times$ scale. The arrow in the images (yellow color reaction) indicates a positive reaction with antibody. The color intensity scale in pixel units per micrometer square $\left(\mathrm{Pixel} / \mu \mathrm{m}^{2}\right)$. As it is seen, the expression of P53 protein in the hypoxia group has increased compared to the control group and decreased in the hypoxia supplement group as compared to the hypoxia group

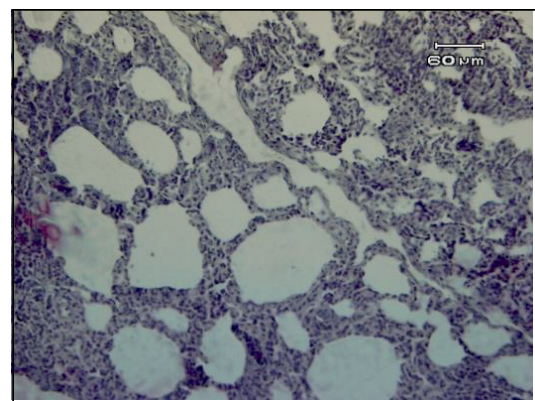

Hypoxia supplement

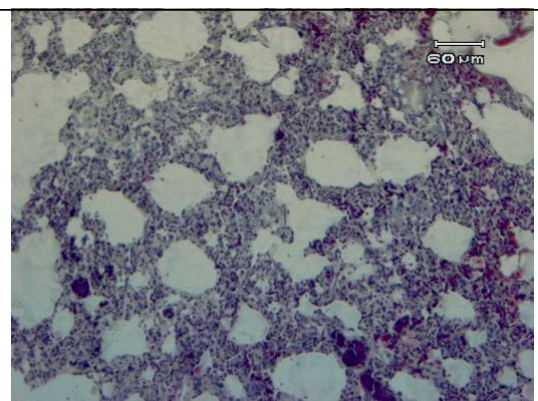

Hypoxia

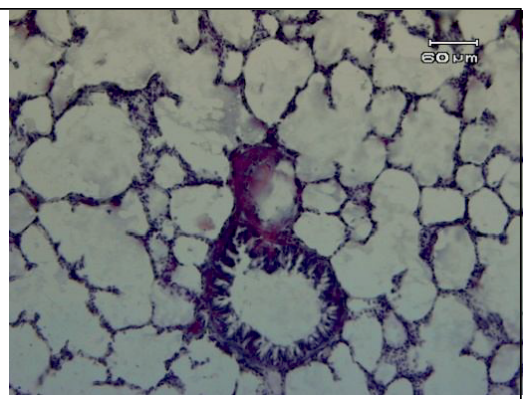

Control

Figure 6. Histological structure of the lung tissue in the 3 studied groups (hematoxylin-eosin staining, $200 \times$ magnification). As seen in Figure 6 , the structure of the parenchymal segment of the lung tissue in the control group was normal, while in the hypoxia group, the number of pulmonary alveoli decreased. Also the number of pulmonary alveoli in the hypoxia supplement group was increased compared to the hypoxia group 
Table 1. Ac-v weight in the extraction process

\begin{tabular}{ll}
\hline $55 \mathrm{gr}$ & Before putting in ethanol \\
$62 / 37 \mathrm{gr}$ & After putting in ethanol \\
$150 \mathrm{ml}$ & Weight of $70 \%$ ethanol which was used \\
$75 / 06 \mathrm{gr}$ & Extract and alcohol soluble weight \\
$6 / 53 \mathrm{gr}$ & Pure extract of Ac-v \\
$1 \mathrm{gr}$ in $10 \mathrm{gr}$ & Percentage of the composition of the extract with drinking water \\
\hline
\end{tabular}

Table 2. The main components of the Ac-v measured by GC-MS analysis

\begin{tabular}{lcc}
\hline Components & The area under the peak (\%) & Retention time (min) \\
\hline 5-(7A-isopropenyl-4,5-dimethyloctahydro-1H-inden-4-yl & 24.49 & 28 \\
n-Hexadecanoic acid & 18.29 & 17 \\
Gamma, Sistosterol & 10.61 & 28 \\
Cis-vaccenic acid & 9.25 & 19 \\
5-(7A-isopropenyl-4,5-dimethyl-octahydroinden-4-YL)-3methy- & 2.63 & 30 \\
I-pent-2-El & & 15 \\
Tetradecanoic acid & 2.20 & 29 \\
Phenanthrene, 9-dodecyltetradecahydro & 2.15 & 24 \\
Squalence & 2.13 & 28 \\
4-(2,6,6-trimethyl-1-cyclohexen-1-YL)-3-penten-2-one & 1.92 & 17 \\
Cis-9-Hexadecenoic acid & 1.78 & 29 \\
2-Azapentane-1,5-dione, 4-methyl-1,5-diphenyl-3-(p-tolyl)- & 1.74 & 24 \\
Hexaethylene glycol monododecyl ether & 1.60 & 26 \\
Vitamin E & 1.58 & 80.37 \\
Total & & \\
\hline
\end{tabular}

\section{Discussion}

The purpose of the study was to investigate the effect of hypoxia and Ac-v extract on the expression of active proteins involved in promoting apoptosis, TNF- $\alpha$, P53 and the respiratory surface of the lungs. Essentially, the findings of the study have shown that after 3 weeks of hypoxia exposure, the expression of TNF- $\alpha$, P53 parenchyma significantly increased, and the lung respiratory surface decreased. It was also observed that Ac-v extract reduced the expression of TNF- $\alpha$ and P53 significantly and increased the respiratory surface of lunge cells in the hypoxia group.

The increase in proteins involved in apoptosis induced by exercise and hypoxia seems to activate apoptotic pathways in the lungs with a reduction in the respiratory surface of the lung in hypoxia. From this, it can be concluded that the molecular and intracellular signaling of apoptosis has led to changes in the lung parenchyma tissue, which is referred to as parenchymal defective remodeling [24, 25]. In recent years, apoptosis has attracted the attention of many physiology researchers. Evidence suggests that apart from cell death in the form of necrosis, apoptosis is also related to exercise training and a decrease in partial oxygen pressures [26]. Excessive or intense exercise may also lead to significant mechanical damage that results in apoptosis and necrosis with inflammatory responses [27]. Extreme exercise activities tend to modify many of the factors that may alter apoptosis in a variety of tissues. Studies have shown that intense exercise activity increases glucocorticoid secretion, intracellular calcium concentrations, and the production of reactive oxygen species - all of them are the factors involved in apoptosis (which has been already described) [27, 28].

The important question is how hypoxia is likely to lead to progression of apoptosis in the lungs and how the TNF- $\alpha$ plays a role in this 
effect. Lung gas exchange failure and circulatory disturbances (during systemic hypoxia) can lead to hypotension and tissue hypoxia, which can induce the release of TNF- $\alpha[29,30]$. The plasma membranes of most cells have what is called death receptors. Death receptors are tumor necrosis factor (TNF) receptor suppressor members. When these receptors are stimulated by ligands, they activate the caspases and induce apoptosis. The feature of this family is the presence of a rich secretion of cysteine in the extracellular part. These receptors in the cytoplasmic section have a sequence called the "death region", and hence they participate in the transmission of apoptotic signaling to the cell [31]. Two important ligands in this pathway are the FAS fascia that attaches to the FAS receptors and TNF- $\alpha$ attached to the TNFR-1 receptor [32].

Hypoxia determines whether the cell responds to hypoxia and survives or dies [33]. In the present study, hypoxia groups lived in a chamber at a simulated artificial height of $2800 \mathrm{~m}$ for 3 weeks. Elevations of 2500 meters or greater would bring significant physiological effects to the body of humans [35]. The low ambient partial pressure of the atmosphere means a low oxygen pressure $\left(\mathrm{pO}_{2}\right)$, which in turn causes oxygen to be limited in the tissues [34].

Shin Daïl et al. [35] examined the effects of long-term intermittent hypoxia on mitochondria and some other factors involved in the apoptotic pathway. The results of their study showed that apoptotic pathway activity depends on mitochondrial BNIP3, caspase 3, caspase 8, caspase 9 and FAS death receptor significantly increased after 4 weeks [35]. An important finding of the present study was the reduction of the levels of proteins involved in apoptosis development and respiratory surface increment of the pulmonary parenchyma in subjects in hypoxia environment after 3 weeks of Ac-v consumption. This point suggests a decreased lung apoptotic activity, increased proliferation of glandular myocytes, and ultimately a positive remodeling of the lung exchange tissue [36]. These findings are likely to support the anabolic action and positive mitochondrial role of Ac-v extract [17]. Cytochrome $\mathrm{C}$ is the causative agent of apoptosis (AIF) which occurs due to the oxidants' activity. The release of cytochrome c into cytosol is assumed as the first apoptotic event [37]. Researchers point out that hypoxia could increase oxidative stress and produce free radicals in the lungs, which may be considered a threat to the lung tissue [38].

Research has shown that the extraction of Ac-v leaves can act as a strong factor in inhibiting free radicals [16]. As a strategy, herbal supplements, which have antioxidative and anti-inflammatory effects on the respiratory tract, can be used to control disease [39]. In this regard, it has been reported that Ac-v inhibits free radicals and improves the antioxidant defense system [39].

Phytochemical evaluation of Ac-v has shown that there is a set of compounds, including flavonoids, terpenoids, phenylpropanoids, carotenoids, carbohydrates, carotenoids and lactic acid in this medicinal plant. Ac-v leaves also contain mucilage, sugar, glycolic acid, tannin, essential oil and a substance called capillarin [40]. Many of these compounds have been proposed as agents having the ability to neutralize free radicals and reduce inflammation. The researchers noted that Ac-v probably leads to these events through direct free radicals control and, consequently, the promotion of antioxidant defense system [41].

The anti-inflammatory activity of Ac-v extract is associated with inflammatory mediator's inhibition such as NO, TNF- $\alpha$, as well as cyclooxygenase enzyme. As previously mentioned, TNF- $\alpha$ is one of the strongest cytokines in apoptosis associated with death receptors. In confirmation of these assumptions, the Ac-v extract was able to inhibit the production of PGE2 due to LPS function, which could also inhibit the production of TNF- $\alpha$ and IL-6 in monocyte macrophage activity. An important part of these inhibitory effects is NF- $\kappa \mathrm{B}$ inactivation [16]. Furthermore, ethyl acetate part of Ac-v has a high percentage of flavonoids and phenolic compounds [42, 43]. As an additional point, studies have shown that p38 is necessary for NF- $\kappa$ B transcription due to TNF stimulation. In the same way, the results have suggested that Ac-v extract may selectively affect the phosphorylation of p38 MAPK and thus have an inhibitory effect on it [16].

\section{Conclusions}

To conclude, it can be argued that chronic moderate hypoxia exposure is a strong stimulant to increase the protein(s) involved in apoptosis pathway (e.g. TNF- $\alpha$ ) and a potential promotor to P53 parenchymal cells, as well as the factor leading to the damage of the parenchyma of the lung by a failed remodeling process. On the other hand, Ac-v extract may possibly reduce the effects of these proteins expression through elements such as flavonoids, terpenoids, phenylpropanoids, and other antioxidant factors, and it can possibly moderate, to some extent, the disruptions caused by hypoxia exposure to lung 
parenchyma. In general, our major finding is that the effects of apoptosis from hypoxia exposure or intense exercise training appear to be mitigated by the (Ac-v) extract usage.

\section{Acknowledgment}

The present study is based on the research project required for military forces (Date of Approval: 18/01/2018, Project Code: 596390), which was funded by the Army Medical University and also universities of Mazandaran and Tabriz. Special thanks to the professors and experts of the mentioned institutes.

\section{Conflict of interest}

There are no direct conflicts of interest with regard to the study or the writing of the manuscript.

\section{References}

1. Amaral SL, Papanek PE, Greene AS. Angiotensin II and VEGF are involved in angiogenesis induced by short-term exercise training. Am J Physiol Heart Circ Physiol. 2001; 281(3): H1163-H1169, doi: 10.1152/ajpheart.2001.281.3.H1163, indexed in Pubmed: 11514283.

2. Dvorak HF, Nagy JA, Feng D, et al. Vascular permeability factor/vascular endothelial growth factor, microvascular hyperpermeability, and angiogenesis. Am J Pathol. 1995; 146(5): 1029-1039, indexed in Pubmed: 7538264.

3. Yan Hl, Xue G, Mei Q, et al. Repression of the miR-17-92 cluster by p53 has an important function in hypoxia-induced apoptosis. EMBO J. 2009; 28(18): 2719-2732, doi: 10.1038/ emboj.2009.214, indexed in Pubmed: 19696742.

4. Liu L, Cash TP, Jones RG, et al. Hypoxia-induced energy stress regulates mRNA translation and cell growth. Mol Cell. 2006; 21(4): 521-531, doi: 10.1016/j.molcel.2006.01.010, indexed in Pubmed: 16483933.

5. Jain M, Sznajder JI. Effects of hypoxia on the alveolar epithelium. Proc Am Thorac Soc. 2005; 2(3): 202-205, doi: 10.1513/ pats.200501-006AC, indexed in Pubmed: 16222038.

6. Höpker K, Hagmann H, Khurshid S, et al. AATF/Che-1 acts as a phosphorylation-dependent molecular modulator to repress p53-driven apoptosis. EMBO J. 2012; 31(20): 3961-3975, doi: 10.1038/emboj.2012.236, indexed in Pubmed: 22909821.

7. Favaloro B, Allocati N, Graziano V, et al. Role of apoptosis in disease. Aging (Albany NY). 2012; 4(5): 330-349, doi: 10.18632/ aging.100459, indexed in Pubmed: 22683550.

8. Vanden Berghe T, Linkermann A, Jouan-Lanhouet S, et al. Regulated necrosis: the expanding network of non-apoptotic cell death pathways. Nat Rev Mol Cell Biol. 2014; 15(2): 135-147, doi: 10.1038/nrm3737, indexed in Pubmed: 24452471.

9. Kayal R, Siqueira M, Alblowi J, et al. TNF- $\alpha$ mediates diabetes -enhanced chondrocyte apoptosis during fracture healing and stimulates chondrocyte apoptosis Through FOXO1. Journal of Bone and Mineral Research. 2010; 25(7): 1604-1615, doi: 10.1002/jbmr.59.

10. Chang NS. A potential role of $\mathrm{p} 53$ and WOX1 in mitochondrial apoptosis (review). Int J Mol Med. 2002; 9(1): 19-24, indexed in Pubmed: 11744990.

11. Speidel D. Transcription-independent p53 apoptosis: an alternative route to death. Trends Cell Biol. 2010; 20(1): 14-24, doi: 10.1016/j.tcb.2009.10.002, indexed in Pubmed: 19879762.

12. Suliman A, Lam A, Datta R, et al. Intracellular mechanisms of TRAIL: apoptosis through mitochondrial-dependent and -independent pathways. Oncogene. 2001; 20(17):
2122-2133, doi: 10.1038/sj.onc.1204282, indexed in Pubmed: 11360196.

13. Volaklis KA, Spassis ATh, Tokmakidis SP, et al. Training and detraining effects of a combined-strength and aerobic exercise program on blood lipids in patients with coronary artery disease. J Cardiopulm Rehabil. 2003; 23(3): 193-200, indexed in Pubmed: 12782903.

14. Matés JM, Sánchez-Jiménez FM. Role of reactive oxygen species in apoptosis: implications for cancer therapy. Int J Biochem Cell Biol. 2000; 32(2): 157-170, indexed in Pubmed: 10687951.

15. Goldfarb AH, Bloomer RJ, McKenzie MJ. Combined antioxidant treatment effects on blood oxidative stress after eccentric exercise. Med Sci Sports Exerc. 2005; 37(2): 234-239, indexed in Pubmed: 15692318.

16. Yuan Q, Zhang X, Liu Z, et al. Ethanol extract of adiantum capillus-veneris L. suppresses the production of inflammatory mediators by inhibiting nf- $\kappa$ b activation. J Ethnopharmacol. 2013; 147(3): 603-611, doi: 10.1016/j.jep.2013.03.046, indexed in Pubmed: 23542147.

17. Nilforoushzadeh MA, Javanmard SH, Ghanadian M, et al. The effects of adiantum capillus-veneris on wound healing: an experimental in vitro evaluation. Int J Prev Med. 2014; 5(10): 1261-1268, indexed in Pubmed: 25400884.

18. Wendakoon C, Calderon P, Gagnon D. Evaluation of selected medicinal plants extracted in different ethanol concentrations for antibacterial activity against human pathogens. Journal of Medicinally Active Plants. 2012; 1(2): 60-68.

19. Schneider JP, Ochs M. Stereology of the lung. Methods Cell Biol. 2013; 113: 257-294, doi: 10.1016/B978-0-12-4072398.00012-4, indexed in Pubmed: 23317906.

20. Harvey BS, Sia TC, Wattchow DA, et al. Interleukin 17A evoked mucosal damage is attenuated by cannabidiol and anandamide in a human colonic explant model. Cytokine. 2014; 65(2): 236-244, doi: 10.1016/j.cyto.2013.10.006, indexed in Pubmed: 24238999.

21. Di Cataldo S, Ficarra E, Acquaviva A, et al. Automated segmentation of tissue images for computerized IHC analysis. Comput Methods Programs Biomed. 2010; 100(1): 1-15, doi: 10.1016/j. cmpb.2010.02.002, indexed in Pubmed: 20359767.

22. Ochs M, Mühlfeld C. Quantitative microscopy of the lung: a problem-based approach. Part 1: basic principles of lung stereology. Am J Physiol Lung Cell Mol Physiol. 2013; 305(1): L15-L22, doi: 10.1152/ajplung.00429.2012, indexed in Pubmed: 23624789 .

23. Kumar S, Samydurai P, Ramakrishnan R, et al. Mass spectrometry Analysis of Bioactive Constuents of Adiantum Capillus -Veneris L. Int J Pharm Pharm Sci. 2014; 6(4): 60-63.

24. Papaioannou AI, Kostikas K, Kollia P, et al. Clinical implications for vascular endothelial growth factor in the lung: friend or foe? Respir Res. 2006; 7: 128, doi: 10.1186/1465-9921-7-128, indexed in Pubmed: 17044926.

25. Bergeron C, Tulic MK, Hamid Q. Tools used to measure airway remodelling in research. Eur Respir J. 2007; 29(3): 596-604, doi: 10.1183/09031936.00019906, indexed in Pubmed: 17329494 .

26. Hammond EM, Giaccia AJ. The role of p53 in hypoxia-induced apoptosis. Biochem Biophys Res Commun. 2005; 331(3): 718-725, doi: 10.1016/j.bbrc.2005.03.154, indexed in Pubmed: 15865928.

27. Phaneuf S, Leeuwenburgh C. Apoptosis and exercise. Med Sci Sports Exerc. 2001; 33(3): 393-396, indexed in Pubmed: 11252065.

28. Arslan S, Erdem S, Sivri A, et al. Exercise-induced apoptosis of rat skeletal muscle and the effect of meloxicam. Rheumatol Int. 2002; 21(4): 133-136, indexed in Pubmed: 11843167.

29. Chandel NS, Trzyna WC, McClintock DS, et al. Role of oxidants in NF-kappa B activation and TNF-alpha gene transcription induced by hypoxia and endotoxin. J Immunol. 2000; 165(2): 1013-1021, doi: 10.4049/jimmunol.165.2.1013, indexed in Pubmed: 10878378.

30. Leeper-Woodford S, Detmer K. Acute hypoxia increases alveolar macrophage tumor necrosis factor activity and alters NF- $\kappa$ B expression. American Journal of Physiology-Lung Cellular and Molecular Physiology. 1999; 276(6): L909-L916, doi: 10.1152/ajplung.1999.276.6.1909. 
31. Burikhanov R, Zhao Y, Goswami A, et al. The tumor suppressor Par-4 activates an extrinsic pathway for apoptosis. Cell. 2009; 138(2): 377-388, doi: 10.1016/j.cell.2009.05.022, indexed in Pubmed: 19632185.

32. Yin XM. Bid, a critical mediator for apoptosis induced by the activation of Fas/TNF-R1 death receptors in hepatocytes. J Mol Med (Berl). 2000; 78(4): 203-211, indexed in Pubmed: 10933582 .

33. Greijer AE, van der Wall E. The role of hypoxia inducible factor 1 (HIF-1) in hypoxia induced apoptosis. J Clin Pathol. 2004 57(10): 1009-1014, doi: 10.1136/jcp.2003.015032, indexed in Pubmed: 15452150 .

34. Kenney WL, Wilmore JH, Costill DL. Physiology of sport and exercise. Human Kinetics. ; 2015.

35. Lee SD, Kuo WW, Lin JA, et al. Effects of long-term intermittent hypoxia on mitochondrial and Fas death receptor dependent apoptotic pathways in rat hearts. Int J Cardiol. 2007; 116(3): 348-356, doi: 10.1016/j.ijcard.2006.03.064, indexed in Pubmed: 16859770.

36. Compernolle V, Brusselmans K, Acker T, et al. Loss of HIF-2alpha and inhibition of VEGF impair fetal lung maturation, whereas treatment with VEGF prevents fatal respiratory distress in premature mice. Nat Med. 2002; 8(7): 702-710, doi: 10.1038/ nm721, indexed in Pubmed: 12053176.

37. Phaneuf S, Leeuwenburgh C. Apoptosis and exercise. Med Sci Sports Exerc. 2001; 33(3): 393-396, indexed in Pubmed: 11252065.

38. Rabbani ZN, Mi J, Zhang Y, et al. Hypoxia inducible factor 1alpha signaling in fractionated radiation-induced lung injury: role of oxidative stress and tissue hypoxia. Radiat Res. 2010 173(2): 165-174, doi: 10.1667/RR1816.1, indexed in Pubmed: 20095848.

39. Morishima N, Nakanishi K, Takenouchi H, et al. An endoplasmic reticulum stress-specific caspase cascade in apoptosis. Cytochrome c-independent activation of caspase- 9 by caspase-12. J Biol Chem. 2002; 277(37): 34287-34294, doi: 10.1074/ jbc.M204973200, indexed in Pubmed: 12097332

40. Sharma G, Chahar M, Dobhal S, et al. Phytochemical constituents, traditional uses, and pharmacological properties of the genus plumeria. Chemistry \& Biodiversity. 2011; 8(8): 1357-1369, doi: 10.1002/cbdv.201000159.

41. Pourmorad F, Hosseinimehr S, Shahabimajd N. Antioxidant activity, phenol and flavonoid contents of some selected Iranian medicinal plants. African journal of Botechnology. 2006; 5(11)

42. Yuan Q, Wang J, Ruan J. Screening for bioactive compounds from Adiantum capillus-veneris L. L J Chem Soc Pak. 2012; 34: 207-216

43. Ichikawa D, Matsui A, Imai M, et al. Effect of various catechins on the IL-12p40 production by murine peritoneal macrophages and a macrophage cell line, J774.1. Biol Pharm Bull. 2004; 27(9): 1353-1358, doi: 10.1248/bpb.27.1353, indexed in Pubmed: 15340218

44. Kasabri V, Al-Hallaq EK, Bustanji YK, et al. Antiobesity and antihyperglycaemic effects of Adiantum capillus-veneris extracts: in vitro and in vivo evaluations. Pharm Biol. 2017; 55(1): 164-172, doi: 10.1080/13880209.2016.1233567, indexed in Pubmed: 27663206. 